\title{
Bacillus Calmette-Guerin (BCG)-induced balanitis following intravesical immunotherapy for urothelial cancer
}

\author{
Santosh Kumar, Yashaswi Thummala, Kalpesh Mahesh Parmar ำ , Abhishek Chandna
}

Urology, Post Graduate Institute of Medical Education and Research, Chandigarh, India

\section{Correspondence to} Dr Kalpesh Mahesh Parmar; kalpesh010385@gmail.com

Accepted 15 March 2021

\section{DESCRIPTION}

A 64-year-old man presented with multiple whitish macules in penis of 1 -week duration. Detailed history revealed that the patient was diagnosed with non-muscle invasive T1 high-grade urinary bladder cancer and planned for intravesical Bacillus Calmette-Guerin (BCG) immunotherapy. The patient received 6 weekly cycles of $120 \mathrm{mg}$ BCG intravesically. On follow-up, the patient reported mild dysuria and noticed one whitish patch over glans penis, which gradually progressed to involve whole of glans in 1 weeks' time. The patient had severe pain and discomfort in the penile region. On examination, his vitals were normal. Local examination showed redness of glans penis with multiple whitish macules present all over the glans which was painful on touch (figure 1). Rest of penis was normal and there were no evidence of body rashes or pigmentation or regional lymphadenopathies. $\mathrm{X}$-ray of the chest was grossly normal. Fine needle aspiration cytology of the lesion revealed granulomatous inflammation with necrosis suggestive of BCG-induced balanitis (figure 2). Further instillation of intravesical BCG was withheld. Routine work up including hemogram, renal, liver function and urine analysis was within normal limits. The patient was started on tablet isoniazid and rifampicin along with oral analgesics for symptomatic relief. At 3 months, lesion waned and antitubercular agents were stopped. As the patient was diagnosed with T1 high-grade urothelial cancer, after complete resolution of symptoms, check cystoscopy showed no evidence of recurrence. Later,

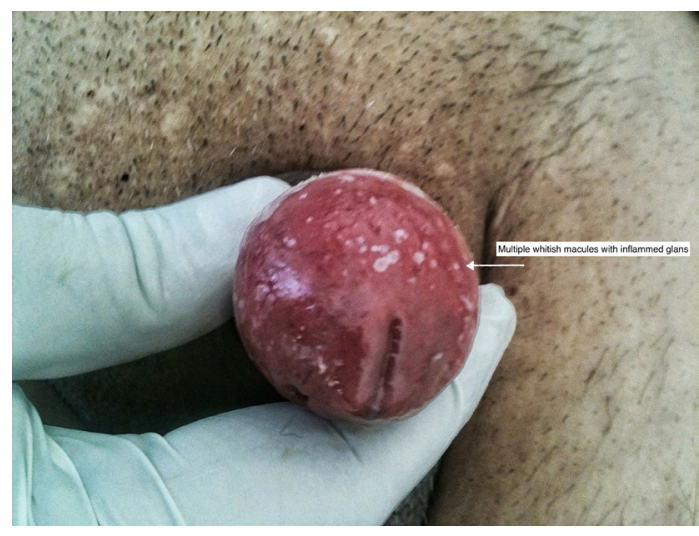

Figure 1 Penis with prepuce retracted showing generalised redness in glans penis suggestive of inflammation and multiple whitish macules of size 0.5 $1 \mathrm{~mm}$ all over the glans penis.

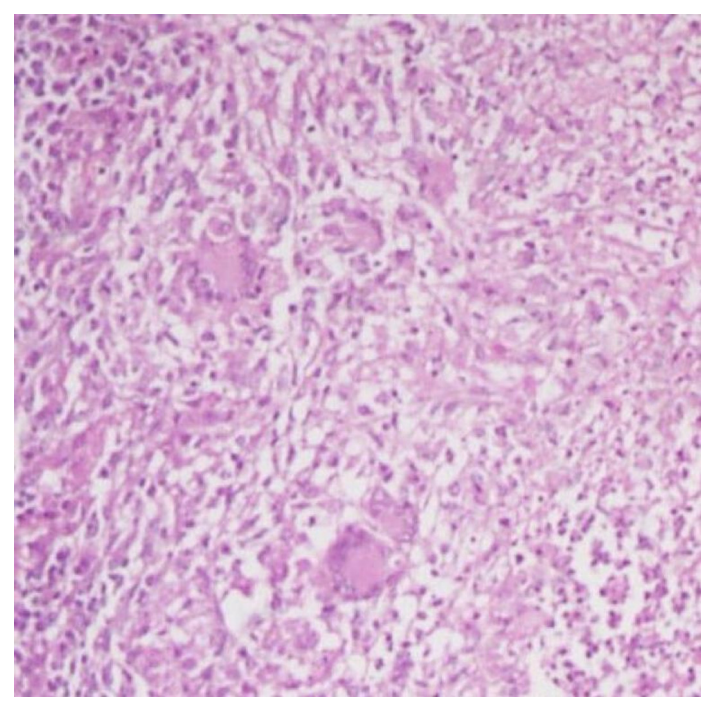

Figure 2 Fine needle aspiration histology image showing caseating granuloma composed of epithelioid histiocytes and central necrosis, with surrounding chronic inflammation.

the patient received 6 weekly cycles of injection gemcitabine $2 \mathrm{~g}$ intravesical instillation followed by monthly injections for 12 months. Check cystoscopy at 3 monthly intervals is normal and shows no evidence of recurrence.

Intravesical BCG is well-established therapy for superficial bladder cancer. Complication is variable and rarely cause systemic sepsis. Granulomatous balanitis is uncommon. ${ }^{12}$ One possible hypothesis is direct penis inoculation by traumatic urethral

\section{Patient's perspective}

I am thankful to whole team of doctors for proper guidance and treatment.

\section{Learning points}

- Bacillus Calmette-Guerin (BCG)-induced balanitis is a rare following intravesical immunotherapy for urothelial cancer.

- One should be aware of this condition as BCG is commonly used for recurrence and progression and non-invasive urinary bladder cancer.

- Prompt diagnosis and treatment is essential to prevent widespread systemic disease. 
catheterisation prior to BCG instillation. ${ }^{3}$ Most patients respond to antitubercular agents. ${ }^{4}$ Further BCG instillation should be avoided and other chemotherapeutic agents may be used. On follow-up, the patient is doing well and has no recurrence on cystoscopy.

Acknowledgements We sincerely thank the patient for consenting for use of images for research work.

Contributors KMP and SK-Design, concept, data collection, manuscript draft and revision. YT and $\mathrm{AC}$ - Images collection and editing.

Funding The authors have not declared a specific grant for this research from any funding agency in the public, commercial or not-for-profit sectors.

Competing interests None declared.

Patient consent for publication Obtained.

Provenance and peer review Not commissioned; externally peer reviewed.
ORCID iD

Kalpesh Mahesh Parmar http://orcid.org/0000-0003-3891-4089

\section{REFERENCES}

1 Brausi M, Oddens J, Sylvester R, et al. Side effects of Bacillus Calmette-Guérin (BCG) in the treatment of intermediate- and high-risk TA, T1 papillary carcinoma of the bladder: results of the EORTC genito-urinary cancers group randomised phase 3 study comparing one-third dose with full dose and 1 year with 3 years of maintenance BCG. Eur Urol 2014;65:69-76.

2 Lestre SIA, Gameiro CD, João A, et al. Granulomas of the penis: a rare complication of intravesical therapy with Bacillus Calmette-Guerin. An Bras Dermato/ 2011;86:759-62.

3 Liu Y, Lu J, Huang Y. Clinical spectrum of complications induced by intravesical immunotherapy of Bacillus Calmette-Guérin for bladder cancer. J Oncol 2019:2019:1-11.

4 Sharma VK, Sethy PK, Dogra PN, et al. Primary tuberculosis of glans penis after intravesical Bacillus Calmette Guerin immunotherapy. Indian J Dermato/ Venereol Leprol 2011;77:47-50.

Copyright 2021 BMJ Publishing Group. All rights reserved. For permission to reuse any of this content visit

https://www.bmj.com/company/products-services/rights-and-licensing/permissions/

BMJ Case Report Fellows may re-use this article for personal use and teaching without any further permission.

Become a Fellow of BMJ Case Reports today and you can:

- Submit as many cases as you like

Enjoy fast sympathetic peer review and rapid publication of accepted articles

- Access all the published articles

Re-use any of the published material for personal use and teaching without further permission

Customer Service

If you have any further queries about your subscription, please contact our customer services team on +44 (0) 2071111105 or via email at support@bmj.com.

Visit casereports.bmj.com for more articles like this and to become a Fellow 